\title{
Treatment of Short Segment Anterior Urethral Stricture: Optical Internal Urethrotomy (OIU) Alone and OIU with Triamcinolone
}

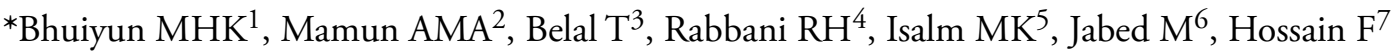

\begin{abstract}
Optical urethrotomy has been considered standard therapy for anterior urethral stricture since its introduction in 1976. Now optical internal urethrotomy (OIU) with intralesional triamcinolone injection is a safe and effective, minimally invasive therapeutic modality. The aim of the study is to compare the outcome of $\mathrm{OIU}$ alone and $\mathrm{OIU}$ with intralesional triamcinolone injection in the treatment of anterior urethral stricture. This Quasi Experimental study was carried out among 50 male patients with bulbar urethral stricture in the Department of Urology, Dhaka Medical College Hospital, Dhaka, over a period of six months. The age range of the patients were 32-46 years and patients were divided equally into two groups, OIU with and without intralesional triamcinolone acetonide injection as Group- $A$ (experimental group, 25 patients) and Group- $B$ (control group, 25 patients). Post-operative evaluation was done on the basis of history and uroflowmetry. Retrograde urethrography and micturating cystourethrography were done only in patient who developed obstructive voiding problems or flow rate below $10 \mathrm{ml} / \mathrm{second}$. Follow up was done at regular interval on $7^{\text {th }}$ day, $3^{\text {rd }}$ month and $\sigma^{\text {th }}$ month. Post-operative outcomes were
\end{abstract}

1. *Dr Mohammad Humayun Kabir Bhuiyun, Assistant Registrar, Department of Urology, Dhaka Medical College Hospital (DMCH), Dhaka. Phone: 01710883556, Email: drhkbhuiyun@gmail.com

2. Dr. Abu Masud Al Mamun, Assistant Registrar, Department of Urology, DMCH, Dhaka.

3. Dr. Towhid Belal, RS, Department of Urology, DMCH, Dhaka.

4. Dr. Rezawanul Haque Rabbani, Resident, Urology, Sir Solimullah Medical College \& Hospital (SSMC), Dhaka.

5. Dr. Md. Khairul Islam, Assistant Registrar, Sarkari Karmachari Hospital, Dhaka

6. Dr. Md. Jabed, Deputy Programme Manager, DGHS, Dhaka

7. Dr. Faruk Hossain, Asst. Professor, Dept. of Urology, Bangabandhu Sheikh Mujib Medical University (BSMMU), Dhaka

*For correspondence compared between two groups. Post-operative infection was significantly higher among those OIU with intralesional Triamcinolone acetonide injection (8\%) than patients without intralesional Triamcinolone acetonide injection (4\%). Per operative extravasations of urine were significantly higher among those without intralesional Triamcinolone acetonide injection (4\%) than subjects with intralesional Triamcinolone acetonide injection. Extravasation not influenced by steroid but this patient subsequently suffered recurrence of stricture. In Group- $A$, pre and post-operative $Q$-max were $10.25 \pm 2.21$ and $22.11 \pm 2.96 \mathrm{ml} / \mathrm{sec}$ respectively. In Group-B, pre and post-operative follow up $Q$-max were $10.37 \pm 2.55$ and $19.54 \pm 2.65 \mathrm{mi} / \mathrm{sec}$ respectively. In Group- $A$, pre and post-operative voiding time was $85.20 \pm 4.20$ and $27.10 \pm 3.36 \mathrm{sec}$ respectively. In Group-B, pre and post-operative follow up voiding time were $86.37 \pm 4.55$ and $31.45 \pm 2.55 \mathrm{sec}$ respectively. Post-operative recurrences of stricture were significantly higher among those without intralesional Triamcinolone acetonide injection (24\%) than subjects with intralesional Triamcinolone acetonide injection (12\%). Post-operative it seems that triamcinolone injection after OIU is safe method to prevent the recurrence of urethral stricture

Keywords: Optical Internal Urethrotomy,Triamcinolone Injection, Urethral Stricture

\section{INTRODUCTION}

The urethral stricture is one of the most known urological diseases and remains with high morbidity refers to scarring process involving the spongy erectile tissue of corpus spongiosum which leads to decrease in caliber of the urethral lumen causing voiding complaints such as weak stream and inclomplete emptying. The natural history of the disease usually begins with a of the urethral mucosa and infection followed by scar. Stricture can develop any part of urethra from the prostatic urethra to the meatus. ${ }^{1}$

A stricture urethra is caused by trauma infection and instrumentation and with noninfectious inflammatory condition like lichen scleorosus. Different type of Trauma represents a very significant etiology of urethral stricture among them saddle trauma is most common. ${ }^{2}$ Saddle 
injuries typically occur during work, bicycle riding, and sports. Overall trauma causes 9.6-36.1\% of stricture urethra. $2,3,4$

Inflammatory strictures secondary to gonorrhea infection were the most commonly seen in the past are less common now due to increasing awareness about sexually transmitted diseases among people. Infectious urethritis is now responsible for only a small proportion of cases. ${ }^{5}$ However, in many cases of anterior urethral stricture disease, the etiology remains unknown. ${ }^{6}$

Urethral stricture disease has always been a challenge for urologists. Many different treatment modalities are available for the treatment of urethral stricture such as dilatation, urethrotomy, stent placement single or two-stage urethroplasty, end to end anastomotic urethroplasty and substitutionurethroplasty. However in clinical practice internal urethrotomy is an easy procedure and is offered as a first time procedure, but the long-term results are inferior to urethroplasty. The major problem with assessing the success rates of internal urethrotomy is that the nature of the strictures that have been treated with internal urethrotomy has been poorly reported. In addition, the literature is not clear regarding the goal of internal urethrotomy. Therefore, in many cases, internalurethrotomy has been reported as successful despite the fact that it has been associated with eventual stricture recurrences. Endoscopic treatment is usually advocated before various forms of urethroplasty are contemplated. Visual internal urethrotomy is simple and safe, causes minimum inconvenience to the patient and requires a short time off work. ${ }^{7}$

With epithelial apposition, wound healing occurs by primary intention.Internalurethrotomy does not provide an epithelial approximation but rather aims to separate the scarred epithelium so that healing occurs secondarily. ${ }^{7}$

Injection of steroids at the site of urethrotomyostensibly prevents scar formation by inhibiting collagen synthesis, increase endogenous collagenase production, and reduces levels of collagenase inhibitors. ${ }^{9}$ Intralesional triamcinolone injection was proposed by Hebert for the first time. ${ }^{8}$

Optical internal urethrotomy with intralesional triamcinolone injection is a safe and effective, minimally invasive therapeutic modality for anterior urethral strictures. ${ }^{7}$ The addition of triamcinolone injection to optical internal urethrotomy site is easy and low costprocedure. ${ }^{9}$ This procedure has significantly reduced the stricture recurrence rate after internal urethrotomy. ${ }^{10}$
Outcome of Intralesional Triamcinolone after OIU does not depend on ages, duration of symptoms or location of stricture.Stricture length, preoperative positive urine culture, previous urethroplasty, neurogenic bladder and history of systemic or immune disease have an important bearing on outcome. For curative and long term effects, this technique deserves to be tested on a large group of patients with special emphasis on objective verification of safety and efficacy profile. Since its introduction in 1976, optical urethrotomy has been considered standard therapy for anterior urethral stricture. Recently the effectiveness of this technique has questioned. ${ }^{10}$ Because of low curative rate several techniques have been used to oppose the process of wound contraction and to prevent stricture recurrence such as indwelling Foley catheter, home clean intermittentself-catheterization etc.Unfortunately, these methods have several complications and often stricture inevitably recurs unless the procedure is continued indefinitely.

Triamcinolone acetonide usedin my study as a potent anti-inflammatory hydrocortisone. This study is aimed toevaluate the efficacy of triamcinolone injection in preventing anterior urethral stricture recurrence after internal urethrotomy as well as we longitudinally time interval between urethrotomy and the recurrence of stricture was observed.

The result of this research helps us to evaluate the outcome optical internal urethrotomy in combination with intralesional triamcinolone injection and the optical internal urethrotomyaloneand to evaluate the recurrence rates after this treatment and also looked the interval between urethrotomy and recurrence of urethral stricture.

In Bangladesh, there is no statistically proven data about the incidence and etiology of the urethral stricture but this group of patients create large crowd in urological centers and day to day urological practice. So effective and appropriate modality should be offered to the patient to reduce the patients suffering and cost.

\section{MATERIALS AND METHODS}

A total of 50 male Patients who admitted in Department of Urology, DMCH with short anterior urethral stricture (10 $\mathrm{mm}$ ) andlength of stricture urethra more than $10 \mathrm{~mm}$, previous unsuccessful attempts of urethroplasty,history of urethral dilatation for stricture urethra,neurogenic bladder, history of systemic immune disease, traumatic urethral stricture,and multiple strictures were excluded from this study. 
Due to time limitation and financial constraint only 50 cases were selected during study period. 50Patients were divided into two groups, Group A: $(\mathrm{n}=25)$ OIU with intralesional triamcinolone acetonide injection and Group $\mathrm{B}:(\mathrm{n}=25)$ OIU without intralesional Triamcinolone acetonide injection.

Before proceeding to operative procedure, proper and detail counseling was done with the patients regarding the operative procedure, possible complications, care of catheter, postoperative follow up and investigations. Inform written consent taken from the patients for operation, for anesthesia, and record and study purpose.A total of 50 patients with symptomatic anterior urethral stricture were taken by purposive sampling technique in department of urology Dhaka medical college hospital,they were divided into Group-A ( $\mathrm{n}=25$, experiment) and Group- $\mathrm{B}(\mathrm{n}=25$, control). The study was approved by the Department of urology Dhaka medical college hospital and BCPS.Informed consent was taken from the patients before enrolment in the study. Patients with completely obliterated urethral stricture were excluded from the study. Patients presenting for the first time for treatment were referred to as primary, whereas those who had undergone some procedure for the treatment of stricture prior to reporting to us were referred to as secondary. Diagnosis of urethral stricture was made on the basis of clinical history, uroflowmetry, and retrograde urethrography. The procedure was done under general or regional anesthesia. The procedure performed with the patient in the lithotomy position under spinal anesthesia.By means of urethrotome with a zero -degree lens,the stricture opening is visualized and a 0.035 inch guidewire is passed through the opening into the bladder.Saline irrigation is utilized to prevent inflammation from the extensive amount of extravasation of irrigation fluid. All patients received antibiotic prophylaxis preoperatively. Optical internal urethrotomy was done in usual manner using cold knife at 12 o'clock position were made through stricture site. In this manner, only fibrous tissue was incised. The incisions were continued until a $20 \mathrm{fr}$ urethral catheter could pass through the stricture site into the bladder.Triamcinolone acetonidewas prepared by $40 \mathrm{mg}$ in $5-10 \mathrm{ml}$ of normal saline and was injected intralesionally at the site of urethrotomy using William's endoscopic needle. At the two edge of incision site $1-2 \mathrm{ml}$ was injected. After confirming free passage of cystoscope into the bladder, an $18 \mathrm{Fr}$ Foley catheter was left in place for 4 days. Broad spectrum antibiotics were administered during perioperative period and continued till first follow up. Some photographs are shown below highlighting the procedure.

Post procedure evaluation was done on the basis of history and uroflowmetry. Retrograde urethrography and micturatingcystourethrography were done only if patient developed obstructive voiding problems or flow rate below $10 \mathrm{ml} / \mathrm{second}$. Follow up was done at regular interval of 7 days, 3 months and 6 months. Any symptoms pertaining to recurrence were noted as reduced stream of urine, retention of urine, and burning micturition.

Demographic information was prospectively. Information included the subject's age, gender, medical qualifications. The gathered data was cross-checked and incomplete questionnaire was discarded. Data was analyzed from 50 completely answered questionnaires by SPSS (Ver. 20; IBM). Data was presented by means of tables and diagrams.

All patients were followed up for at least for six months by history regarding fever, dysuria, urinary stream, post micturation dribbling, sense of incomplete evacuation, and examination of external genitalia( penis, urethra, scrotum, testes, to exclude any purulent discharge and direct observation of urine flow), suprapubic area, both loin, and systemic examination when necessary.

During first follow up at 7 th day after removal of penile catheter all patients followed up with Ultrasonogram of KUB with PVR, Uroflowmetry. During second follow up at 3rd month all patients went to Ultrasonogram of KUB with PVR, Uroflowmetry, RGU \& MCU when Qmax $<15 \mathrm{ml} / \mathrm{sec}$. at the time of 6 month, all patients went to final follow up with Ultrasonogram of KUB with PVR, RGU \& MCU when $Q \max <15 \mathrm{ml} / \mathrm{sec}$ and Urethrocystoscopy if narrow urethra in RGU \&MCU.

All data were recorded systematically in preformed data collection form and quantitative data was expressed as mean and standard deviation and qualitative data was expressed as frequency distribution and percentage.

\section{RESULTS}

Total of 50 patients with bulbar urethral stricture age from $32-46$ years were included in this study according to the selection criteria. Patients were divided into two groups, Group A: OIU with intralesional Triamcinolone acetonideinjection and Group B: OIU without intralesional Triamcinolone acetonideinjection. All the 
subjects were age matched. All the subjects had bulbar urethral stricture. Pre-operative and postoperative data were collected and analyzed.

Majority of the respondents were in between 36 to 40 (38\%) followed by $26 \%$ between 35 and below and $41-45$ age respectively among the 50 respondents. Only 10\% respondents were age between 46 and above.

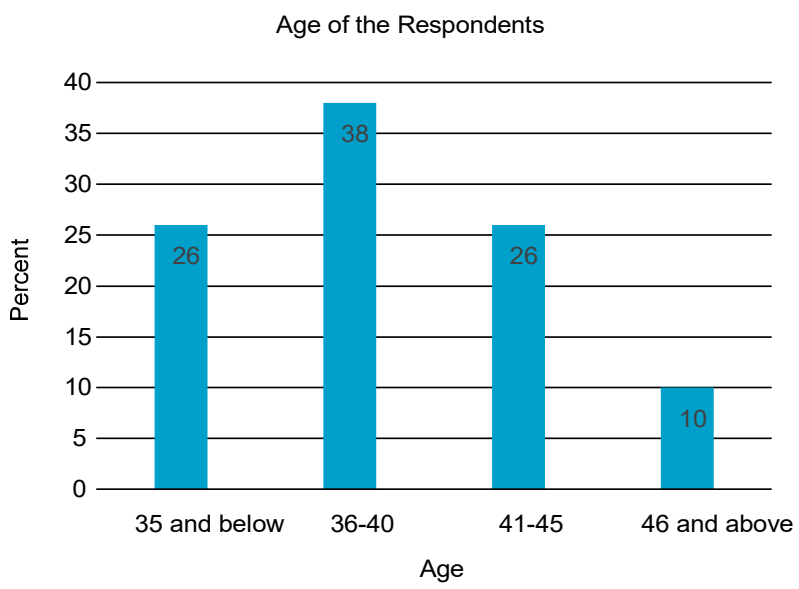

Figure-1: Age of the respondents

The mean age of group-A and Group-B was 39.92 \pm 6.13 and $40.01 \pm 5.99$ years respectively. There was no significant difference of mean age between the groups ( $p>0.05$ ).

Table- I: Age of the respondents (in years)

\begin{tabular}{|c|c|c|c|c|c|}
\hline \multirow[t]{2}{*}{ Age range } & \multicolumn{2}{|c|}{$\begin{array}{c}\text { Group- A } \\
(\mathrm{n}=25)\end{array}$} & \multicolumn{2}{|c|}{$\begin{array}{c}\text { Group- B } \\
(\mathrm{n}=25)\end{array}$} & \multirow[t]{2}{*}{$\begin{array}{c}\mathrm{p} \\
\text { value }\end{array}$} \\
\hline & No & $\%$ & No & $\%$ & \\
\hline 35 and below & 06 & 24.00 & 07 & 28.00 & \multirow{5}{*}{0.748} \\
\hline $36-40$ & 09 & 36.00 & 10 & 40.00 & \\
\hline $41-45$ & 07 & 28.00 & 06 & 24.00 & \\
\hline 46 and above & 03 & 12.00 & 02 & 08.00 & \\
\hline Mean $\pm S D$ & \multicolumn{2}{|c|}{$39.92 \pm 6.13$} & \multicolumn{2}{|c|}{$40.01 \pm 5.99$} & \\
\hline
\end{tabular}

\# Student's t-test was used to analyze the data.

Group A: OIU with intralesional Triamcinolone acetonide injection

Group B: OIU without intralesional Triamcinoloneacetonide injection

Pre-operativemean Q-max of Group-A and Group-B were $10.25 \pm 2.21$ and $10.37 \pm 2.55 \mathrm{ml} / \mathrm{sec}$ respectively. After 6 months post-operative mean Q-max of Group-A and Group-B were $22.11 \pm 2.96$ and $19.54 \pm 2.65 \mathrm{ml} / \mathrm{sec}$ respectively.
Table II: Comparison of Q-max $(\mathrm{ml} / \mathrm{sec})$ between two groups at 3 months.

\begin{tabular}{|c|c|c|c|c|}
\hline & $\begin{array}{c}\text { Number of } \\
\text { patients }\end{array}$ & $\begin{array}{l}\text { Q-max } \\
(\mathrm{ml} / \mathrm{sec})\end{array}$ & $\begin{array}{c}\text { Mean } \pm \\
\text { SD }\end{array}$ & $\begin{array}{c}\mathrm{p}- \\
\text { value }\end{array}$ \\
\hline \multirow{3}{*}{$\begin{array}{l}\text { Group A } \\
\mathrm{n}=25\end{array}$} & 10 & 23 & \multirow{3}{*}{$22.25 \pm 1.15$} & \multirow{8}{*}{0.045} \\
\hline & 8 & 22 & & \\
\hline & 6 & 25 & & \\
\hline \multirow{5}{*}{$\begin{array}{l}\text { Group B } \\
\mathrm{n}=25\end{array}$} & 1 & 13 & \multirow{5}{*}{$20.25 \pm 1.10$} & \\
\hline & 10 & 22 & & \\
\hline & 7 & 20 & & \\
\hline & 5 & 23 & & \\
\hline & 3 & 12 & & \\
\hline
\end{tabular}

Table III: Comparison of Q-max $(\mathrm{ml} / \mathrm{sec})$ between two groups at 6 months.

\begin{tabular}{|c|c|c|c|c|}
\hline & $\begin{array}{c}\text { Number of } \\
\text { patients }\end{array}$ & $\begin{array}{l}\text { Q-max } \\
(\mathrm{ml} / \mathrm{sec})\end{array}$ & $\begin{array}{c}\text { Mean } \pm \\
\text { SD }\end{array}$ & $\begin{array}{c}\mathrm{p}^{-} \\
\text {value }\end{array}$ \\
\hline \multirow{4}{*}{$\begin{array}{l}\text { Group A } \\
n=25\end{array}$} & 10 & 22 & \multirow{4}{*}{$22.11 \pm 2.96$} & \multirow{9}{*}{0.042} \\
\hline & 7 & 24 & & \\
\hline & 5 & 25 & & \\
\hline & 3 & 13 & & \\
\hline \multirow{5}{*}{$\begin{array}{l}\text { Group B } \\
\mathrm{n}=25\end{array}$} & 10 & 22 & \multirow{5}{*}{$19.54 \pm 2.65$} & \\
\hline & 5 & 24 & & \\
\hline & 4 & 21 & & \\
\hline & 3 & 12 & & \\
\hline & 3 & 10 & & \\
\hline
\end{tabular}

\# Student's t-test was used to analyze data and were presented as mean $\pm \mathrm{SD}$.

Group A: OIU with intralesional Triamcinolone acetonideinjection

Group B: OIU without intralesional Triamcinolone acetonide injection

Pre-operative mean voiding time of Group-A and Group-B were $85.20 \pm 4.20 \mathrm{sec}$ and $86.37 \pm 4.55 \mathrm{sec}$ respectively. After 6 months post-operative mean voiding time of Group-A and Group-B were $26.18 \pm 2.25$ secand $35.45 \pm 2.55$ secrespectively and voiding time in group- $B$ was significantly higher than group-A. 
Table IV: Comparison of voiding time (in sec) between two groups at 3 months.

\begin{tabular}{|c|c|c|c|c|}
\hline & $\begin{array}{c}\text { Number } \\
\text { of patients }\end{array}$ & $\begin{array}{l}\text { Voiding time } \\
\text { (in sec) }\end{array}$ & $\begin{array}{c}\text { Mean } \pm \\
\text { SD }\end{array}$ & $\begin{array}{c}\mathrm{p}- \\
\text { value }\end{array}$ \\
\hline \multirow{4}{*}{$\begin{array}{l}\text { Group A } \\
\mathrm{n}=25\end{array}$} & 10 & 25 & \multirow{4}{*}{$\begin{array}{c}25.28 \pm \\
2.15\end{array}$} & \multirow{8}{*}{0.042} \\
\hline & 8 & 24 & & \\
\hline & 6 & 23 & & \\
\hline & 1 & 50 & & \\
\hline \multirow{4}{*}{$\begin{array}{l}\text { Group B } \\
n=25\end{array}$} & 10 & 25 & \multirow{4}{*}{$\begin{array}{c}29.28 \pm \\
2.25\end{array}$} & \\
\hline & 7 & 26 & & \\
\hline & 5 & 24 & & \\
\hline & 3 & 60 & & \\
\hline
\end{tabular}

Table V: Comparison of voiding time (in sec) between two groups at 6 months

\begin{tabular}{|c|c|c|c|c|}
\hline & $\begin{array}{c}\text { Number } \\
\text { of patients }\end{array}$ & $\begin{array}{l}\text { Voiding time } \\
\text { (in sec) }\end{array}$ & $\begin{array}{c}\text { Mean } \pm \\
\text { SD }\end{array}$ & $\begin{array}{c}\mathrm{p}- \\
\text { value }\end{array}$ \\
\hline \multirow{4}{*}{$\begin{array}{l}\text { Group A } \\
n=25\end{array}$} & 10 & 22 & \multirow{4}{*}{$\begin{array}{l}26.18 \\
\pm 2.25\end{array}$} & \multirow{9}{*}{0.038} \\
\hline & 7 & 19 & & \\
\hline & 5 & 23 & & \\
\hline & 3 & 25 & & \\
\hline \multirow{5}{*}{$\begin{array}{l}\text { Group B } \\
n=25\end{array}$} & 10 & 25 & \multirow{5}{*}{$\begin{array}{c}35.45 \pm \\
2.55\end{array}$} & \\
\hline & 5 & 28 & & \\
\hline & 4 & 24 & & \\
\hline & 3 & 65 & & \\
\hline & 3 & 70 & & \\
\hline
\end{tabular}

\# Student's t-test was used to analyze the data.

Group A: OIU with intralesional Triamcinolone acetonide injection

Group B: OIU without intralesional Triamcinolone acetonide injection

Post-operative recurrences of stricture were significantly higher among those without intralesional Triamcinolone acetonideinjection (24\%) than subjects with intralesional Triamcinolone acetonideinjection (12\%).

Table VI: Comparison of rate of stricture recurrence between two groups on RGU and MCU findings at 3 months:

\begin{tabular}{|l|c|c|c|c|c|}
\hline & \multicolumn{3}{|c|}{ RGU and MCU findings } & \multirow{2}{*}{ Rate \%(n) } & \multirow{2}{*}{$\begin{array}{c}\text { p- } \\
\text { value }\end{array}$} \\
\cline { 2 - 4 } & Normal(n) & Stricture(n) & Length $(\mathrm{mm})$ & & 0.018 \\
\hline Group A n=25 & 24 & 01 & $9 \pm 00$ & $04 \%(01)$ & 0.018 \\
\hline Group B n=25 & 21 & 03 & $8 \pm 1.80$ & $12 \%(03)$ & \\
\hline
\end{tabular}

Table VII: Comparison of rate of stricture recurrence between two groups on RGU and MCU findings at 6 months:

\begin{tabular}{|l|c|c|c|c|c|}
\hline & \multicolumn{3}{|c|}{ RGU and MCU findings } & \multirow{2}{*}{$\begin{array}{c}\text { Rate } \% \\
(\mathrm{n})\end{array}$} & $\begin{array}{c}\text { p- } \\
\text { value }\end{array}$ \\
\cline { 2 - 4 } & Normal(n) & Stricture(n) & Length $(\mathrm{mm})$ & $12 \%$ & 0.021 \\
\hline Group A $\mathrm{n}=25$ & 22 & 03 & $9 \pm 1.10$ & $12 \% \%$ & \\
\hline Group B $\mathrm{n}=25$ & 19 & 06 & $11 \pm 1.20$ & $24 \%$ \\
\hline
\end{tabular}

\# Chi square test was used to analyze data and were presented as mean $\pm \mathrm{SD}$.

Group A: OIU with intralesional Triamcinolone acetonide injection

Group B: OIU without intralesional Triamcinolone acetonide injection

Post-operative UTI was significantly higher among those OIU with intralesional Triamcinolone acetonide injection (8\%) than subjects with OIU without intralesional Triamcinolone acetonideinjection (4\%).Prophylactic antibiotic continued upto first follow up and there were no UTI patients found at that follow up. There are different complications occur during OIU like Haemorrhage, extravasation of urinespongiocavarnosal fistula, erectile dysfunction, penile pain,paraesthesia of the glans penis and incontinence but these but these but these are not influence by steroid. 
Table VIII: Comparison of post-operative UTI between two groups at 3 months

\begin{tabular}{|c|c|c|c|}
\hline & UTI & Rate, \%(n) & p-value \\
\hline Group A, n=25 & 02 & $08 \%(2)$ & 0.012 \\
\hline Group B, n=25 & 00 & $00 \%(0)$ & \\
\hline
\end{tabular}

Table IX: Comparison of post-operative UTI between two groups at 6 months

\begin{tabular}{|c|c|c|c|}
\hline & UTI & Rate, \%(n) & p-value \\
\hline Group A, n=25 & 02 & $08 \%(2)$ & 0.016 \\
\hline Group B, n=25 & 01 & $04 \%(0)$ & \\
\hline
\end{tabular}

\# Chi square test was used to analyze the data.

\section{DISCUSSION}

Total of 50 patients with bulbar urethral stricture age from 32-46 years were included in this study according to the selection criteria.All patients were not given CISC advice and kept the catheter for four days. Patients were divided into two groups, Group A: OIU with intralesional triamcinolone acetonideinjection and Group B: OIU without intralesional triamcinolone acetonide injection. All the subjects were age matched. All the subjects had bulbar urethral stricture. The mean age of group-A and Group-B was $39.92 \pm 6.13$ and $40.01 \pm 5.99$ years respectively. There was no significant difference of mean age between the groups ( $p>0.05$ ). In previous study Kumar et al, (2014) observed that median age at presentation of anterior urethral stricture was 47 years (17-80 years).

In present study post-operative infection was significantly higher among those OIU with intralesional Triamcinolone acetonides injection (8\%) than subjects with OIU without intralesional Triamcinolone acetonide injection (4\%). Per operative extravasations of urine were significantly higher among those without intralesional Triamcinolone acetonideinjection (4\%) than subjects with intralesional Triamcinolone acetonide injection but this result not influenced by steriod. Tabassi et al. ${ }^{11}$ observed that in the experimental group with intralesion Triamcinolone acetonide, 1 (2.94\%), 3 (8.82\%), and $2(5.8 \%)$ patients developed infection, bleeding, and extravasation, respectively. In the control group, infection, bleeding, and extravasation occurred in 2 (5.55\%), 3 (8.33\%), and 2 $(5.55 \%)$ patients, respectively.
Current study also revealed that in Group-A, pre and post-operative Q-max were $10.25 \pm 2.21$ and $22.11 \pm 2.96$ $\mathrm{ml} /$ sec respectively. In Group-B, pre and postoperativefollow up Q-max were $10.37 \pm 2.55$ and $19.54 \pm 2.65 \mathrm{ml} / \mathrm{sec}$ respectively. Time interval of recurrence among group-A and group-B $4.64 \pm 1.35$ and $3.15 \pm 1.85$ respectively.Tabassi et al. ${ }^{11}$ observed that time to recurrence decreased significantly in experimental group $(8.08 \pm 5.55$ versus $3.6 \pm 1.59$ months $)(\mathrm{p}<.05)$.

In this present study post-operative recurrences of stricture were significantly higher among those without intralesional Triamcinolone acetonide injection (24\%) than subjects with intralesional Triamcinolone acetonideinjection (12\%) which was statistically significant $(\mathrm{p}<.05)$. In a study by Kumar et al. ${ }^{12} 2014$ overall recurrence rate after OIU with TA was $19.4 \%$ (20 out of 103 patients). Mazdak et al. ${ }^{6}$ 2009 reported study on 25 patients treated by internal urethrotomy and intraurethralsubmucosal triamcinolone injection. Recurrence was seen in 5 out of 24 patients $(21.7 \%)$ and among 21 patients treated only by internal urethrotomy recurrence was seen in 11 patients (50\%).

Korhonen and colleagues reported transurethral injection of steroid for treatment of urethral strictures. Of 38 patients, 21 underwent internal urethrotomy while 17 patients received triamcinolone injection after internal urethrotomy.Urethrotomy was done at 12 o'clock position and catheter was removed one day after the surgery. Recurrence rate was $71 \%$ in patients who underwent internal urethrotomy and $61 \%$ in those who received triamcinolone. Similarly, Ishigooka et al. ${ }^{13}$ mentioned that the recurrence rate was only $4.4 \%$ in short stricture $(1 \mathrm{~cm}$ or shorter), while it was $42.9 \%$ in longer strictures.

Tabassi et al. ${ }^{11}$ studied 70 patients of urethral stricture who were treated with internal urethrotomy and intraurethral triamcinolone injection. Recurrence was noted in 12 patients out of 34 and in 15 patients out of 36 in control group. Recurrence rate was lower in experimental group but the difference did not reach statistical significant (35.3\% versus $41.7 \%)(\mathrm{P}=.584)$. Hradec et al. ${ }^{14}$ observed in case series that patients treated by urethrotomy without corticoid injection the rate of recurrent stricture was $19.4 \%$. Using a specially constructed needle for injection of triamcinolone acetonide, the recurrence rate was reduced to $4.3 \%$.

However, in this study, the difference between recurrence rates was statistically significant. Considering that we did not use clean intermittent self-catheterization, the 
similarity of the results in these two studies suggests that triamcinolone injection during internal urethrotomy combined with a urethral catheterization program may decrease the recurrence rate significantly.In this study,we measured recurrence rate, Q-max and voiding time.

\section{CONCLUSIONS}

OIU combined with intralesional injection significantly reduced the strictures recurrence rate and able to delay the onset of recurrence by inhibit collagen synthesis, increase endogenous collagenase production, and reduces levels of collagenase inhibitors. One of the limitations of the present study is related to the timing of the outcome evaluation. The present study has a post-operative follow up period of only 6 months, which is a relatively short period. Magnetic resonance urethrographyand ultrasonography should have done to delineate the length of fibrosis more accurately which could help to plan operative procedure more precisely. But we were unable to do so because of unavailability of the facility in the study place.

\section{REFERENCES}

1. Latini JM. Minimally invasive treatment of urethral strictures in men. Current Bladder dysfunction Reports. 2008; 3:111-6.

2. Palminteri E, Berdondini E, Verze $P$, et al. Contemporary urethral stricture characteristics in the developed world. Urology 2013; 112:830-4. [PubMed]

3. Stein DM, Thum DJ, Barbagli G,et al. A geographic analysis of male urethral stricture aetiology and location. BJU Int 2013;112:830-4. [PubMed]

4. Fenton AS, Morey AF, Aviles R, et al. Anterior urethral stricture : Etiology and characteristics. Urology 2005;65:1055-8. [PubMed]

5. Lumen N, Hoebeke P, Willemsen P, et al. Etiology of urethral strictures disease in the 21 st century. J Urol. 2009;182:983-7. [PubMed]

6. Mazdak, H.,Izadpanahi,MH.,Ghalamkari, A.,Kabiri, M.,Khorrami,MH.andMahdavi, KN. Internal urethrotomy and intraurethralsubmucosal injection of triamcinolone in short bulbar urethral strictures. IntUrolNephrol. 2009; 42(5), 565-569.

7. Kumar,S., Kapoor,A.,Ganesamoni, R., Nanjappa, B., Sharma,V.and Mete,KM.Efficacy of Holmium laser Urethrotomy in combination with intralesional triamcinolone in the treatment of anterior urethral stricture,Korean Journal of Urology. 2012;53(9), 614-618.

8. Hebert PW. The treatment of urethral stricture: intralesional injection triamcinolone. J Urol. 1972; 108:745-7.

9. Jordan, G.H., 2012. Surgery of the penis and urethra. In: A.J. WEIN, ed. Campbell-Walsh Urology.2012; 1(10): 956-1000.

10. Mazdak, H., Meshki, I. and Ghassami, F. Effect of mytomycin-c on anterior urethral stricture recurrence after internal urethrotomy. EurUrol, 2006; 51(2): 1089-1092.

11. Tabassi, KT., Yarmohamadi, A. andMohammdi, S.Triamcinolone Injection Following Internal Urethrotomy for Treatment of urethral Stricture. Urology Journal. 2011; 8(2): 132-136.

12. Kumar, S., Garg, N., Singh, K. and Mandal,AK.. Efficacy of Optical Internal Urethrotomy and Intralesional Injection of Vatsala-Santosh PGI Tri-Inject (Triamcinolone, Mitomycin C, and Hyaluronidase) in the Treatment of Anterior Urethral Stricture. Ad Uro. 2014; 5(2): 234-238.

13. Ishigooka M, Tomaru M, Hashimoto T, Sasagawa I, Nakada T, Mitobe K. Recurrence of urethral stricture after single internal urethrotomy. International Urology and Nephrology. 1995; 27(1):101-6.

14. Hradec, E., Jarolin,L. and Petrik, R.Optical internal urethrotomy for stricture of male urethra; Effect of local steroid injection. Eur Urol. 1981; 7(3):165-168.

15. Abourachid H., Louis D., Goudot, B., Dahmani F. Hakimi, F.andDaher, N.Internal urethrotomy in the treatment of stenosis of urethra.Late results and review of literature.JUrol(Paris). 1989;95(5): 477-80.

16. Andrich, DE. \& Mundy, AR.Urethral stricture and their surgical management, BJU Int. 2000; 86(4): 571-580

17. Barbagli, G.,Selli, C., Tosto, A. and Palmintiri, E. Dorsal free graft urethroplasty, J Urol, 1996; 155(3):123-126.

18. Bullock,TL.andBrandes, SB. Adult Anterior Urethral Strictures: A National Practice Patterns Survey of Board Certified Urologists in the United States.AJU.2007; 177 (2):685-690. 
19. Chung, GH., Kang, DH. AndChoi, HY. The effects of hyaluronic acid and carboxymethylcellulose in preventing recurrence of urethral stricture after endoscopic internal urethrotomy: a multicenter, randomized controlled, single-blinded study. Journal of Endourology. 2013;27 (6):756-762.

20. Dixon, CM.,Hricak, H. and McAninch, JW.Magnetic resonance imaging of traumatic posterior urethral defects and pelvic crush injuries. J Urol.1998; 148(2):1162.

21. Hosseeini, J., kaviani, A. and Golshan,AR.Clean intermittent catheterization with triamcinolone ointment following internal urethrotomy. Urol J. 2008; 5(4): 265-268.

22. Korhonen, P., Talja, M., Ruutu, M.and Alfthan, O. Intralesional Corticosterioid Injections in Combination with internal Urethrotomy in the Treatment of Urethral Strictures. International urology and Nephrology. 1989; 22(3): 263-269.

23. Shirazi, M.,Khezri, A.,Samani,SM.,Monabbati, A.,Kojoori, J. andHassanpour,A.Effect of intraurethral captopril gel on the recurrence of urethral stricture after direct vision internal urethrotomy: Phase 2 clinical trial.Int J Urol. 2007; 14(4): 203. 